\title{
Diferenciação de populações ovinas encontradas no estado do Piauí
}

\author{
Biagiotti, D. ${ }^{1} ;$; Sarmento, J.L.R. ${ }^{2}$; Rego Neto, A.A. ${ }^{3}$; Santos, N.P.S. ${ }^{3}$; Figueiredo Filho, L.A.S. ${ }^{3}$; Santos, G.V. ${ }^{3}$; Torres, T.S. ${ }^{3}$ \\ e Sena, L.S. ${ }^{4}$
}

'Colégio Técnico de Bom Jesus. Universidade Federal do Piauí. Bom Jesus-PI. Brasil.

${ }^{2}$ Centro de Ciências Agrarias. Universidade Federal do Piauí. Teresina-PI. Brasil.

${ }^{3}$ Pós-Graduação em Ciência Animal. Universidade Federal do Piauí. Teresina-Pl. Brasil.

4Pós-Graduação em Zootecnia. Universidade Federal do Piauí. Bom Jesus-PI. Brasil.

\section{PALAVRAS CHAVE ADICIONAIS}

Análise de agrupamento.

Análise de componente principal.

Análise de correspondência.

Genótipos.

Método Ward.

\section{RESUMO}

Objetivou-se analisar a semelhança fenotípica entre genótipos de ovinos localizados em oito microrregiões do Estado do Piauí, para averiguação da semelhança de caracteres morfométricos de animais da raça Santa Inês com os de outras raças da região, utilizando-se de análise multivariada. Nos rebanhos amostrados foram encontrados animais das raças Santa Inês, Dorper e Morada Nova, presente uma ou mais raça simultaneamente. As características morfológicas avaliadas foram tipo de pelagem e perfil do chanfro, já as métricas foram a altura de cernelha, a altura de garupa, a circunferência torácica, o comprimento corporal e o comprimento de orelha. Essas características foram avaliadas com as raças estratificadas por microrregião e, através da análise de componentes principais e de agrupamento de Ward, analisou-se a semelhança fenotípica entre as raças e também a variação dentro da raça Santa Inês, com base na relação entre as características medidas. Constatou-se que a raça Santa Inês apresentou variação no tamanho de acordo com a microrregião e que se apresenta com maior altura, mas com menor comprimento e perímetro corporal que a Dorper no Piauí. Já a Morada Nova foi a menor em tamanho. A raça Santa Inês apresentou um grupo de animal com maior tamanho corporal, localizado nas microrregiões de Floriano, Médio Parnaíba Piauiense, Campo Maior e Teresina. Outro grupo de tamanho intermediário, porém com comprimento corporal e circunferência torácica maior e orelha pequena, localizado na microrregião de São Raimundo Nonato, e um terceiro grupo, com tamanho intermediário, orelhas grandes e animais menores, localiza-se nas microrregiões do Litoral Piauiense e Valença. Pela análise de correspondência das características morfológicas com tipo de chanfro e o tipo de pelagem, foi possível identificar que os animais da raça Dorper no Estado apresentam alta correspondência com a característica lanada, que pode ser considerado uma desvantagem por estar numa região que prevalece alta temperatura ao durante $o$ ano.

\section{Differentiation of ovine populations found in Piaui state}

\section{SUMMARY}

\section{AdDITIONAL KEYWORDS \\ Cluster analysis. \\ Principal component analysis. \\ Correspondence analysis. \\ Genotypes. \\ Ward method.}

\section{INFORMACIÓN}

Cronología del artículo.

Recibido/Received: 4.12.2013

Aceptado/Accepted: 28.10 .2014

On-line: 16.3 .2015

Correspondencia a los autores/Contact e-mail:

biagiotti@ufpi.edu.br
The objective of this work was to analyze, using multivariate analysis, the phenotypic similarity between genotypes of sheep located in eight microregions of Piauí state considering morphometric traits of Santa Ines animals related to those of other breeds in the region. Animals of Santa Inês, Dorper and Morada Nova breeds were found. The haircoat type, chamfer profile, height at withers, rump height, thoracic circumference, body length and ear length, were the characteristics assessed on sheeps stratified by microregion, using the principal components and cluster of Ward analyses; the phenotypic similarity among breeds and the variation within the Santa Ines breed, was established on the relationships between the characteristics measured. Santa Ines breed showed variation in size according to the microregion; it was the higher breed, but with shorter length and body perimeter than Dorper sheep in Piauí. Morada Nova sheeps were the smallest. Santa Ines breed showed a group of animals with the larger body size, located in the regions of Floriano, Piauí Middle Parnaiba, Campo Maior and Teresina, another group of animals of intermediate size, but with larger body length and thoracic circumference and small ear, located in the microregion of Sao Raimundo Nonato and a third group of intermediate size, with big ears and smaller animals is located in the regions of the Piaui Coast and Valença. From the correspondence analysis with morphological characteristics, was found that Dorper animals in Piaui state exhibit high correlation with the woolly characteristic that can be considered a disadvantage for being in a region where high temperature prevails during the year. 


\section{INTRODUÇÃO}

A disponibilidade de informação sobre cruzamentos entre raças de ovinos exploradas no Nordeste do Brasil ainda é muito limitada, portanto é desconhecido o risco da introdução de genes oriundos de raças especializadas em carne nas raças locais, em consequência da utilização de cruzamentos indiscriminados e sem estudos prévio de eficiência, o que pode conduzir a prejuízos genéticos e econômicos consideráveis para o sistema de produção em uso (Selaive-Villarroel e Souza Júnior, 2005), além do agravante de colocar em risco a preservação e a sustentabilidade das raças locais.

No desejo por animais com rápido crescimento, melhores carcaças e melhor habilidade materna gerou descontrolada busca por animais melhoradores. Dado o caráter imediatista do brasileiro, alguns criadores utilizaram raças importadas, especializadas na produção de carne, para realizarem cruzamento com as raças nativas.

Na região Nordeste a raça Santa Inês é relatada por Cartaxo et al. (2008), por apresentarem alta rusticidade e adaptabilidade da raça Santa Inês às condições ambientais da região, uma causa de rebanhos de fêmeas estarem sendo utilizados como matriz em cruzamentos com a raça Dorper, em busca de melhorarias no desempenho e nas características de carcaças dos cordeiros resultantes desse cruzamento.

As situações descritas tornam-se preocupantes por dois motivos: o primeiro é porque pode está havendo diluição da raça Santa Inês como patrimônio genético, colocando em dúvida a identidade da raça nos rebanhos da região, consequentemente pode necessitar de atenção com sua conservação como raça pura. $\mathrm{O}$ segundo motivo está no fato de que se tem divulgado que a raça vem sofrendo processo de melhoramento genético por meio de seleção, entretanto, alguns criadores têm praticado cruzamentos desordenados e produzido novos indivíduos que, mesmo parecendo-se fenotipicamente com a raça Santa Inês, herdam atributos morfométricos e produtivos diferentes do verdadeiro Santa Inês, o que dificilmente seria alcançado em pouco tempo de seleção, dadas as falhas de escrituração zootécnica existentes na quase totalidade dos arquivos dos criadores. Esta situação merece especial atenção por parte dos técnicos e pesquisadores militantes da ovinocultura, uma vez que está em jogo a consolidação e a sustentabilidade da mais importante raça de ovinos deslanados brasileira. Nesse processo, a utilização de caracteres morfológicos permite caracterizar ou classificar indivíduos e raças de uma população (Oliveira et al., 2006).

A caracterização fenotípica dos animais tem sido comumente associada à definição do padrão racial, mas também tem sido aplicada no contexto da sustentabilidade (Neto et al., 2006), as características morfológicas podem gerar informações úteis na determinação das relações genéticas entre raças ou populações em geral, podendo auxiliar no encontro de ancestrais em comum ou parentesco entre animais, possibilitando agrupar os animais de uma mesma espécie em raças distintas (Oliveira et al., 2006; Dossa et al., 2007).
Consoante o exposto, objetivou-se, com o estudo, analisar semelhança fenotípica entre genótipos de ovinos explorados no Estado do Piauí, com destaque para a averiguação da semelhança de caracteres morfométricos de animais da raça Santa Inês com os de outras raças encontradas na região.

\section{MATERIAL E MÉTODOS}

Os dados desta pesquisa foram coletados em rebanhos de ovinos provenientes de diferentes microrregiões do Estado do Piauí, definidas pelo Instituto Brasileiro de Geografia e Estatística (IBGE, 2010), como Litoral Piauiense, Teresina, Campo Maior, Valença do Piauí, Médio Parnaíba Piauiense, São Raimundo Nonato, Floriano e Alto Médio Gurguéia. A importância da criação de ovinos foi fundamental na escolha dessas microrregiões, onde são encontrados animais criados para fins de exposição e também animal para criação comercial.

Foram coletadas informações em 1040 fêmeas ovinas adultas encontradas em criatórios localizados nas microrregiões citadas. A coleta dos dados ocorreu no período de 2009 a 2011, amostrando-se apenas rebanhos nos quais se tinha conhecimento prévio da existência de animais puro da raça Santa Inês. Porem, em cada rebanho mensurou-se todos os exemplares adultos dos diferentes genótipos presentes.

A decisão por coletar informações em animais adultos se pautou em Bueno et al. (2001), pois para os autores não há mais variação considerável no comprimento corporal quando o animal atinge a maturação esquelética, por isso os animais avaliados devem ser adultos.

As médias morfométricas tomadas nos animais da raça Santa Inês e demais genótipos encontrados foram as alturas de cernelha (AC) e garupa (AG), circunferência torácica (CIRC), comprimento de orelhas $(\mathrm{CO})$ e comprimento do animal (CC), todas em centímetros; além de características morfológicas como tipo de pelagem (lanado, lanugem e deslanado) e tipo de chanfro (convexo, semi-convexo e retilíneo). A mensuração das medidas morfométricas corporais foi realizada com o auxílio de uma fita métrica, com o animal mantido em posição correta de aprumo. A altura de cernelha corresponde à medida entre o ponto mais alto da cernelha até a extremidade distal do membro anterior; a altura da garupa compreende a medida entre o ponto mais alto da garupa do animal até a extremidade do membro posterior; o comprimento de orelha foi tomado da base até a extremidade desta; o comprimento do animal foi mensurado da ponta da escápula até a ponta do ísqueo; e, a circunferência torácica foi medida passando a fita em torno do tórax do animal, próximo às axilas.

Para a classificação do tipo de pêlo do animal foram consideradas as seguintes classes: animal deslanado (com ausência completa de lã no corpo, somente a presença de pêlos); animal com lanugem (presença de fibra grossa de aparência esbranquiçada na área dorsal e posterior do corpo); e animal lanado (com presença de lã por todo o corpo). Enquanto para a classificação do tipo de chanfro do animal foram consideradas as seguintes classes: animal com chanfro retilíneo, ou seja, sem protuberância na parte superior do chanfro; 
chanfro convexo, com muita protuberância, ou chamado de encarneirado e chanfro semi-convexo, pouca protuberância na parte superior.

Após a coleta, os dados foram armazenados em planilhas eletrônicas para posterior análise. Todas as análises foram realizadas considerando as medidas tomadas na raça Santa Inês por microrregião e as medidas dos demais genótipos encontrados, independente das microrregiões. Para as análises, foi utilizado o logiciário estatístico SAS versão 9.0 para o emprego de análises estatísticas descritivas simples (média, desvio padrão e coeficiente de variação) através do procedimento MEANS; a análise de variância realizada pelo PROC GLM e as médias foram comparadas através do teste SNK a 5 \%; as frequências das características morfológicas foram feitas com o auxílio do procedimento FREQ; e, as correlações entre as características mensuradas foram calculadas utilizando o procedimento CORR do mesmo logiciário.

Para o estudo de diversidade fenotípica foi realizada a análise de componentes principais (ACP), com o auxílio do PROC PRINCOMP do SAS, que permitiu agrupar as populações com base em medidas de similaridade. A distribuição espacial dos indivíduos, pelos componentes principais, permite identificar os grupos genéticos mais similares, importantes, por exemplo, na formação dos grupos das microrregiões e ainda, uma primeira visualização do grau de uniformidade entre indivíduos dentro de cada população.

O método de análise de componentes principais, utilizando a matriz de correlação, consiste em transformar um conjunto de variáveis $X_{1}, X_{2}, \ldots ., X_{n}$ em um novo conjunto de variáveis $Y_{1}\left(C_{1}\right), Y_{2}\left(C_{2}\right), \ldots, Y_{n}\left(C P_{n}\right)$, sendo que cada componente principal é uma combinação linear das características:

$$
\mathrm{CP}=a_{i 1} X_{1}+a_{i 2} X_{2}+\ldots+a_{i n} X_{n}=\sum_{j=1}^{p} a_{j} z_{j}
$$

$\operatorname{com} i$ e $j=1,2, \ldots, \mathrm{n}$

Após encontrar os componentes principais, pode-se afirmar que o primeiro componente $\mathrm{CP}_{1}$ é o que explica a maior variância existente na população, o segundo componente explica a segunda maior variância existente e assim sucessivamente, até que se complete o conjunto $\mathrm{n}$ de componentes principais.

Assim a ideia principal por trás desse procedimento é a de que poucos, dentre os primeiros componentes principais, expliquem a maior variabilidade dos dados originais, o que permite descartar os demais componentes racionalmente, reduzindo o número de variáveis.

Foi necessária a padronização destas variáveis $X$ $(j=1,2, \ldots, n)$, pois a estrutura de dependência de $X_{j}$ foi dada pela matriz de correlação R. Dessa forma, a diferença das escalas de medidas das variáveis foi retirada pelo uso de variáveis reduzidas (variáveis padronizadas), conforme apresentado a seguir: em que:

$$
Y_{i j}=\frac{X_{i j}-\bar{X}_{j}}{\sigma\left(X_{j}\right)}
$$

$Y_{i j}=$ variável padronizada no indivíduo $i$, na caracte-

$X_{i j}=$ valor observado no indivíduo $i$, na característica $j$;

$X_{j}=$ média estimada da característica $j$;

$\sigma\left(X_{j}\right)=$ desvio-padrão dos dados da característica $j$.

Os autovalores da matriz de correlação corresponderam às variâncias de cada componente e os autovetores normalizados corresponderam aos coeficientes de ponderação das características padronizadas.

A dissimilaridade foi obtida a partir da relação entre pares de populações, considerando que a alta dissimilaridade entre populações indica que tais são distantes tendo como base as medidas morfométricas amostradas (Rencher, 2002). Calculando a dissimilaridade e, depois, utilizando o método de agrupamento Ward, a partir do qual se calcula o menor aumento da variância intragrupo para gerar os agrupamentos e, consequentemente, os dendrogramas.

O método de Ward não calcula distâncias entre grupos. Mas para a formação dos grupos é feita a maximização da homogeneidade dentro dos grupos, ou minimização do total das somas de quadrados dentro de cada grupo, também conhecida como soma de quadrados de erros. Em cada passo do procedimento, são formados grupos de tal modo que a solução resultante tenha a menor soma de quadrados dentro de grupos (Dias, 2009). Para a escolha adequada do método de agrupamento foi calculado o valor do coeficiente de correlação cofenética (CCC) proposto por Sokal e Rohlf (1962). Quanto maior o valor obtido para CCC, menor será a distorção provocada pelo agrupamento. Segundo Rohlf (1970), na prática, dendrogramas com CCC menor que 0,7 indicam a inadequação do método de agrupamento para resumir a informação do conjunto de dados.

Para um intervalo de confiança para os dendrogramas construídos através dos métodos hierárquicos, foi realizada a técnica de bootstrap com auxilio do programa Genes v 6.0 (Cruz, 2008), ou seja, foram feitas 1000 reamostragens do dendrograma, a partir das quais se obteve a porcentagem de replicações similares aos dados originais.

Após a análise de agrupamentos, foi realizada a análise de correspondência para tentar associar os grupos formados pela análise de agrupamento, na qual se empregaram médias com distribuição contínua e frequências de ocorrência dos dados categóricos (tipo de pelo e perfil do chanfro), que permitem analisar graficamente as relações existentes entre os grupos. Para isso, utilizou o procedimento CORRESP do SAS, por meio do qual foram obtidos os valores de coeficiente de dimensão a partir das linhas e colunas de tabela de contingência e, com esses valores, foram construídos os gráficos. Com os gráficos produzidos, pôde-se avaliar visualmente se as variáveis de interesse afastaram-se do pressuposto de independência, sugerindo possí- 
Tabela I. Características morfométricas de ovinos de raças exploradas no Estado do Piauí (Morphometric characteristics of sheep breeds explored in the State of Piauí).

\begin{tabular}{|c|c|c|c|c|c|}
\hline Genótipos & AG (cm) Média $\pm D P$ & $\mathrm{AC}(\mathrm{cm})$ Média $\pm \mathrm{DP}$ & CC (cm) Média & $\mathrm{CO}(\mathrm{cm})$ Média $\pm \mathrm{DP}$ & CIRC (cm) Média $\pm D P$ \\
\hline Dorper & $63,96 \pm 4,55^{b}$ & $64,33 \pm 3,80^{b}$ & $74,64 \pm 5,46^{a}$ & $11,95 \pm 1,34^{b}$ & $90,71 \pm 9,84^{a}$ \\
\hline Morada Nova & $60,68 \pm 2,48^{c}$ & $60,04 \pm 2,35^{c}$ & $59,48 \pm 4,11^{\mathrm{c}}$ & $10,32 \pm 0,85^{c}$ & $75,88 \pm 4,07^{c}$ \\
\hline Santa Inês & $71,37 \pm 4,91^{\mathrm{a}}$ & $71,35 \pm 5,25^{a}$ & $70,27 \pm 6,56^{b}$ & $15,81 \pm 1,99^{a}$ & $86,40 \pm 9,55^{b}$ \\
\hline
\end{tabular}

$\mathrm{AG}=$ altura garupa; $\mathrm{AC}=$ altura cernelha; $\mathrm{CC}=$ comprimento corporal; $\mathrm{CO}=$ comprimento orelha; $\mathrm{CIRC}=$ circunferência torácica; $\mathrm{DP}=$ desvio padrão.

a,b,cMédias seguidas de mesma letra na coluna não diferem $(p>0,05)$ pelo teste Student-Newman-Keuls.

veis associações e, ainda, perceber como se dá esta associação. Os níveis das variáveis de linha e de coluna assumem posições nos gráficos de acordo com a associação ou similaridade entre elas (Greenacre, 2007).

\section{RESULTADOS E DISCUSSÃO}

Nas visitas às propriedades em busca por animais da raça Santa Inês, quando animais de outras raças foram encontrados, também foram mensurados para servir como uma base de comparação entre os genótipos e associar as medidas corporais entre os indivíduos.

As medidas corporais dos diferentes genótipos de ovinos encontrados no Estado do Piauí estão na tabela I, os resultados das médias das medidas corporais estão próximos ao do estudo realizado por Carneiro et al. (2010), no que diz respeito às raças Santa Inês, Morada Nova e Dorper.

Carneiro et al. (2010), pesquisando animais da raça Morada Nova, Santa Inês e Dorper no território brasileiro, encontraram resultados de medidas parecidos, nos quais os animais da raça Santa Inês apresentam

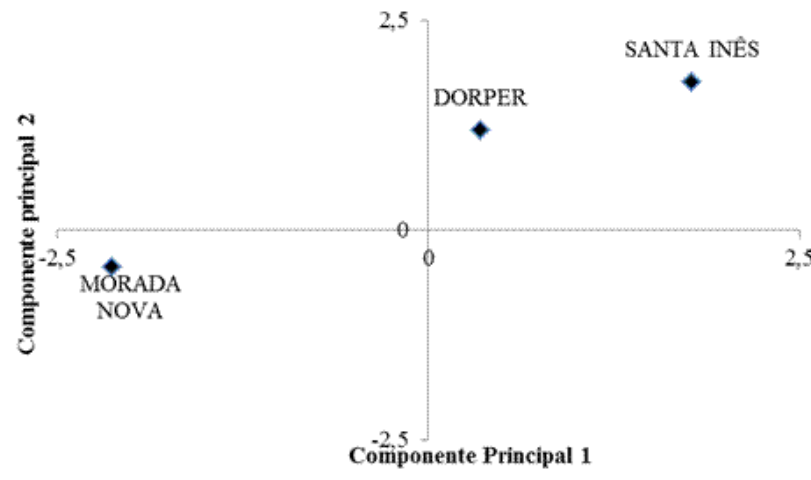

Figura 1. Gráfico contendo as coordenadas dos dois principais componentes em relação às diferentes raças de ovinos encontradas do Piauí (Graphic containing the coordinates of the two main components for the different breeds of sheep found Piauí). maior altura, ao passo que os animais da raça Dorper apresentam maior circunferência torácica e os animais da raça Morada Nova apresentam menor porte de tamanho.

Com as medidas biométricas coletadas nas diferentes raças deseja-se comparar as raças e posteriormente averiguar se existe algo em comum entre as mesmas. Para isso, optou-se por analisar as características em conjunto através da análise multivariada, já que analisar e interpretar cada característica isoladamente geraria dificuldades. Primeiramente, realizou-se a análise de componentes principais, e, após a obtenção da média de cada raça e análise da variabilidade explicada pelos componentes estimados, verificou-se que os dois primeiros componentes explicaram $100 \%$ da variação total existente nos dados, demonstrando que a técnica de componente principal foi efetiva para reduzir a dimensionalidade dos dados, possibilitando a análise em um plano cartesiano, ou seja, bidimensional, ao invés da análise de cinco características simultaneamente, sem a perda de informação (figura 1).

Como a representação gráfica dos escores de componentes principal demonstrou-se haver proximidade entre as raças Dorper e Santa Inês, optando-se pela análise de agrupamento, utilizando o método de Ward, que consiste num método hierárquico precursor de métodos de agrupamentos não hierárquicos que aperfeiçoam algum critério para dividir os dados em certo número de grupos elípticos. Neste método, consideram-se, para formação inicial do grupo, aqueles indivíduos que proporcionam a menor soma de quadrado dos desvios (figura 2).

Realizada a análise de agrupamento, verificou-se (figura 2) que os animais das raças Dorper e Santa Inês estão em uma mesma ramificação, com confiabilidade de $100 \%$ obtida através da ferramenta de bootstrap, isso permite levantar a hipótese de indivíduos mais semelhantes entre estas duas raças, o que pode ser indicativo de cruzamentos entre as raças, confirmando o levantamento de Paiva et al. (2005) sobre a formação do Novo Santa Inês, ou seja, animais maiores, robustos,

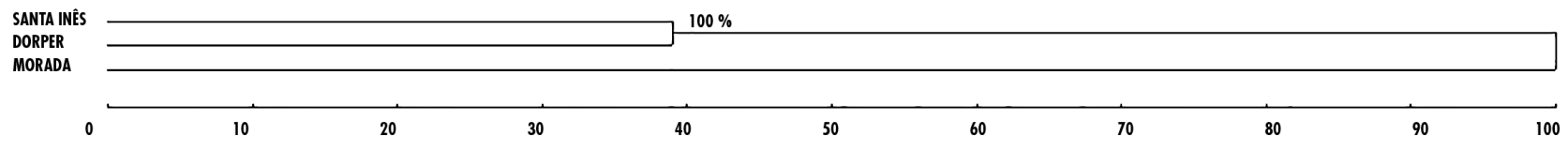

Figura 2. Agrupamento das diferentes raças de ovinos encontradas do Piauí pelo método Ward com valores de bootstrap com confiabilidade acima de $50 \%$ (Clustering of different breeds of sheep found by the Ward method of Piauí with bootstrap values of above $50 \%$ reliability). 
Tabela II. Características biométricas de ovinos da raça Dorper, Morada Nova e as microrregiões encontradas com a raça Santa Inês no estado do Piauí (Biometric characteristics of Dorper, Morada Nova and microregions found with Santa Inês breed in the State of Piauí).

\begin{tabular}{|c|c|c|c|c|c|c|}
\hline Microrregiões & $\mathrm{N}$ & AG & $A C$ & $\mathrm{CC}$ & $\mathrm{CO}$ & CIRC \\
\hline Alto Médio Gurguéia & 340 & $71,76^{\mathrm{ab}}$ & $71,43^{\mathrm{bc}}$ & $69,28^{b}$ & $15,88^{\mathrm{a}}$ & $84,90^{\mathrm{cd}}$ \\
\hline Teresina & 108 & $73,82^{\mathrm{a}}$ & $74,11^{\mathrm{a}}$ & $74,24^{a}$ & $16,59^{a}$ & $94,05^{a}$ \\
\hline Floriano & 44 & $73,15^{a}$ & $73,75^{\mathrm{ab}}$ & $72,28^{a}$ & $16,07^{a}$ & $89,31^{b c}$ \\
\hline Médio Parnaíba Piauiense & 36 & $73,89^{a}$ & $73,10^{\mathrm{ab}}$ & $73,62^{a}$ & $16,57^{a}$ & $88,00^{b c}$ \\
\hline Campo Maior & 178 & $71,82^{\mathrm{ab}}$ & $72,90^{\mathrm{ab}}$ & $72,06^{a}$ & $16,61^{\mathrm{a}}$ & $86,97^{b c}$ \\
\hline São Raimundo Nonato & 85 & $70,47^{\mathrm{bc}}$ & $66,65^{d}$ & $68,08^{\mathrm{bc}}$ & $13,62^{c}$ & $89,01^{b c}$ \\
\hline Valença & 152 & $68,13^{d}$ & $69,37^{c}$ & $68,41^{\mathrm{bc}}$ & $15,00^{\mathrm{b}}$ & $82,30^{\text {de }}$ \\
\hline Litoral Piauiense & 34 & $69,08^{\mathrm{cd}}$ & $69,38^{c}$ & $65,79^{c}$ & $16,38^{\mathrm{a}}$ & $80,38^{e}$ \\
\hline Raça Dorper & 38 & $63,96^{\mathrm{e}}$ & $64,33^{\mathrm{e}}$ & $74,64^{a}$ & $11,95^{d}$ & $90,71^{\mathrm{b}}$ \\
\hline Raça Morada Nova & 25 & $60,68^{f}$ & $60,04^{f}$ & $59,48^{d}$ & $10,32^{\mathrm{e}}$ & $75,88^{f}$ \\
\hline
\end{tabular}

$\mathrm{N}=$ número; $\mathrm{AG}=$ altura garupa; $\mathrm{AC}=$ altura cernelha; $\mathrm{CC}=$ comprimento corporal; $\mathrm{CO}=$ comprimento orelha; $\mathrm{CIRC}=$ circunferência torácica. a,b,c,dMédias seguidas de mesma letra na coluna não diferem $(p>0,05)$ pelo teste Student-Newman-Keuls.

com característica de raças especializadas em carne, que propiciam melhor conformação de carcaça e mais rápido acúmulo de gordura na carcaça. Resultado semelhante foi obtido por Carneiro et al. (2010), que encontraram maior proximidade entre animais Santa Inês e Dorper do que Santa Inês e Morada Nova no Nordeste Brasileiro.

Após constatar que os animais da raça Santa Inês possuem semelhança com animais da raça Dorper, conforme a análise de agrupamento, decidiu-se encontrar em qual microrregião do Estado essas semelhanças eram maiores. Para isso foram coletadas as medidas corporais dos animais Santa Inês nas microrregiões e tais foram comparadas com os genótipos Dorper e Morada Nova (tabela II).

Através do teste de comparação de médias é possível visualizar grupos com médias estaticamente diferentes $(\mathrm{p}<0,05)$, como no caso da altura de garupa, as microrregiões de Teresina, Floriano, Médio Parnaíba Piauiense possuem os animais mais altos, o que ocorre também quanto à altura de cernelha (tabela II). Referente ao comprimento corporal, como discutido anteriormente, os animais da raça Dorper possuem maior comprimento corporal, o que não diferiu estatisticamente dos animais da raça Santa Inês criados nas microrregiões de Teresina, Floriano, Médio Parnaíba Piauiense e Campo Maior. A microrregião do Alto Médio Gurguéia possui animais de porte intermediário em relação às outras microrregiões do Estado (tabela II), isto pode ser fruto da própria seleção natural.

Os animais pertencentes à microrregião de São Raimundo Nonato possuem baixa altura de cernelha e garupa, além de intermediário comprimento corporal; porém a característica de circunferência torácica é destaque nesses animais, resultados parecidos com os animais da raça Dorper (tabela II). Segundo Traoré et al. (2008), as medidas biométricas têm apresentado bons resultados na discriminação de populações quando são consideradas várias medidas simultaneamente no estudo.

Após constatação da presença de animais de outras raças no Estado do Piauí, e com a hipótese de animais da raça Dorper sendo utilizados em cruzamentos com a raça Santa Inês, parte-se para a busca de microrregiões que possam estar mais próximas a esta situação. Para poder comparar os animais da raça Santa Inês das diferentes microrregiões com os genótipos de Dorper e Morada Nova encontrados no Estado do Piauí, com as diferentes medidas corporais sendo analisadas e interpretadas em conjunto, lança-se mão da análise multivariada, pois esse tipo de análise permite observar as cinco medidas corporais conjuntamente, através da análise por componente principal, cujo intuito é a redução do número de variáveis em um mínimo de componentes que explicam a máxima variação dentro dos indivíduos. Feita a análise de componentes principais envolvendo as microrregiões criadoras de Santa Inês e as outras duas raças, pôde-se verificar que os dois primeiros componentes explicam $96 \%$ da variação total existente (tabela III).

Mesmo a análise gerando cinco componentes principais, somente os dois primeiros componentes explicam mais de $96 \%$ da variabilidade, sendo que o primeiro componente explica $77 \%$ da variação total e o segundo, aproximadamente, $19 \%$, tornando, assim, os demais componentes passíveis de descarte. De acordo com Cruz e Carneiro (2006), as variáveis de maiores pesos nos primeiros autovetores são consideradas de maior importância para o estudo de diversidade, quando o autovalor explica uma fração considerável da variação disponível, normalmente limitada a um valor mínimo de $80 \%$.

Tabela III. Autovalores associados aos componentes principais (CP) obtidos a partir de características biométricas de ovinos no Estado do Piauí (Eigenvalues associated with principal components obtained based on biometric sheep characteristics in the State of Piauí).

\begin{tabular}{lcrr}
\hline CP & Autovalor & VS (\%) & VA (\%) \\
\hline 1 & 3,852 & 77,04 & 77,04 \\
2 & 0,964 & 19,29 & 96,33 \\
3 & 0,140 & 2,79 & 99,12 \\
4 & 0,025 & 0,49 & 99,61 \\
5 & 0,019 & 0,39 & 100,00 \\
\hline
\end{tabular}

VS= variação simples; VA= variação acumulada. 
Tabela IV. Coeficientes dos componentes principais das características morfométricas de diferentes genótipos de ovinos encontrados em rebanhos no estado do Piauí (Coefficients of the principal components of the morphometric characteristics of different genotypes of sheep found in flocks in the State of Piauí).

\begin{tabular}{|c|c|c|c|c|c|}
\hline \multicolumn{6}{|c|}{ Componentes principais } \\
\hline & 1 & 2 & 3 & 4 & 5 \\
\hline$A G$ & 0,480625 & $-0,243306$ & $-0,566005$ & $-0,388689$ & 0,488222 \\
\hline$A C$ & 0,485406 & $-0,280742$ & 0,142803 & $-0,354557$ & $-0,734480$ \\
\hline $\mathrm{CC}$ & 0,424791 & 0,507224 & 0,615265 & $-0,266955$ & 0,335352 \\
\hline $\mathrm{CO}$ & 0,447695 & $-0,461577$ & $-0,461577$ & 0,691770 & 0,190429 \\
\hline CIRC & 0,390516 & 0,625825 & 0,625825 & 0,416413 & $-0,271023$ \\
\hline
\end{tabular}

$\mathrm{AG}=$ altura de garupa; $\mathrm{AC}=$ altura de cernelha; $\mathrm{CC}=$ comprimento corporal; $\mathrm{CO}=$ comprimento de orelha; $\mathrm{CIRC}=$ circunferência torácica .

Os coeficientes de ponderação de cada componente em relação às medidas morfométricas estão apresentados na tabela IV.

As medidas de alturas de cernelha, garupa e comprimento de orelha foram nessa ordem as que apresentaram maiores coeficientes de ponderação para o primeiro componente, enquanto que, para o segundo componente, a maior ponderação deu-se para a medida de circunferência torácica.

A partir dos escores dos coeficientes de ponderação dos dois primeiros componentes principais juntamente com a média de cada raça e cada microrregião formouse o plano cartesiano bidimensional com os valores dos dois primeiros componentes (figura 3). Com a representação gráfica dos dois principais componentes, percebe-se que os animais da raça Santa Inês estão mais próximos aos indivíduos da raça Dorper que dos da Morada Nova, sendo que algumas microrregiões aproximam-se entre si (figura 3 ).

No entanto, na análise por componentes principais, as visualizações gráficas das distâncias podem levar a distorções, o que pode incorrer em erros de agrupa-

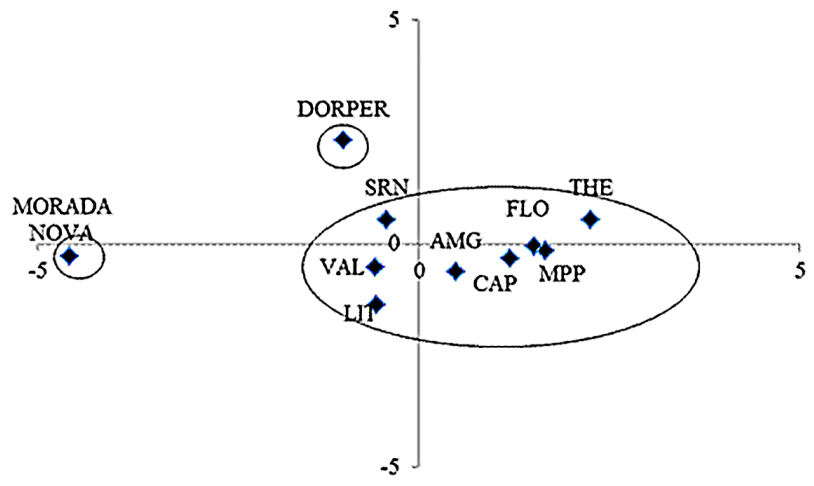

Figura 3. Dispersão de ovinos Dorper, Morada Nova e de grupos de animais Santa Inês de microrregiões do Piauí, com as coordenadas do gráfico com os dois primeiros componentes principais obtidos com características morfométricas (Sheep dispersion of Dorper, Morada Nova and Santa Ines groups of microregions of Piauí, with coordinates on the graph with the first two principal components obtained from with morphometric characteristics).

SRN: São Raimundo Nonato; VAL: Valença do Piauí; LIT: Litoral Piauiense; AMG: Alto Médio Gurguéia; CAM: Campo Maior; FLO: Floriano; MPP: Médio Parnaíba Piauiense; THE: Teresina. mentos, para contornar esse tipo de distorção fez-se uso da análise de agrupamento pelo método Ward (figura 4).

Com a utilização da ferramenta de bootstrap, na qual são realizadas 1000 reamostragens dos agrupamentos para uma maior confiabilidade da formação do dendrograma, pôde-se ter a confiabilidade dos grupos a partir de valores de bootstrap acima de $50 \%$.

Através da análise de agrupamento entre os animais pertencentes às diferentes microrregiões do Estado do Piauí em que foram encontrados animais da raça Santa Inês em conjunto com os outros dois genótipos encontrados no Estado, Dorper e Morada Nova, obser-

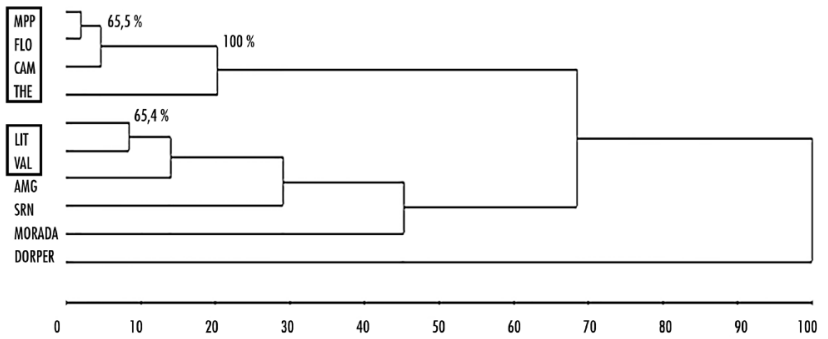

Figura 4. Disposição dos grupos de genótipos de ovinos encontrados no Estado do Piauí com valores de bootstrap com confiabilidade acima de $50 \%$ (Disposal of sheep genotype groups found in Piauí state with bootstrap values reliably above $50 \%$ ).

SRN: São Raimundo Nonato; VAL: Valença do Piauí; LIT: Litoral Piauiense; AMG: Alto Médio Gurguéia; CAM: Campo Maior; FLO: Floriano; MPP: Médio Parnaíba Piauiense; THE: Teresina.

va-se que o primeiro grupo foi formado pelas microrregiões Litoral Piauiense e Valença, o segundo grupo por animais pertencentes à microrregião do Alto Médio Gurguéia, o terceiro grupo por ovinos pertencentes à microrregião de São Raimundo Nonato e o último grupo fora composto pelos animais das microrregiões de Campo Maior, Floriano, Médio Parnaíba Piauiense e Teresina. Sendo que os genótipos Dorper e Morada Nova constituem cada um, separadamente, um grupo diferenciado, em que não há agrupamento com microrregião criadora de Santa Inês, entretanto pode-se perceber a aproximação entre os animais da microrregião de São Raimundo Nonato com esses genótipos. Esse tipo de análise de agrupamento baseam-se na maior homogeneidade entre os indivíduos formados por cada grupo. A linha em destaque, separando os 
Tabela V. Características $(\mathrm{cm})$ de ovinos da raça Santa Inês, estratificados por grupo segundo a microrregião de localização, e de animais Dorper e Morada Nova no Piauí (Characteristics of Santa Ines sheep clustered according to microregion and Dorper and Morada Nova in Piauí animals).

\begin{tabular}{lllllll}
\hline Grupos & Microrregião & AG & AC & CC & CO & CIRC \\
\hline Grupo 1 & LIT e VAL & $68,31^{\mathrm{c}}$ & $69,38^{\mathrm{c}}$ & $67,94^{\mathrm{b}}$ & $15,25^{\mathrm{c}}$ & $81,95^{\mathrm{b}}$ \\
Grupo 2 & AMG & $71,76^{\mathrm{ab}}$ & $71,43^{\mathrm{b}}$ & $69,28^{\mathrm{b}}$ & $15,89^{\mathrm{b}}$ & $84,90^{\mathrm{b}}$ \\
Grupo 3 & SRN & $70,47^{\mathrm{b}}$ & $66,65^{\mathrm{d}}$ & $68,08^{\mathrm{b}}$ & $13,62^{\mathrm{d}}$ & $89,01^{\mathrm{a}}$ \\
Grupo 4 & CAM, FLO, MPP e THE & $72,78^{\mathrm{a}}$ & $73,38^{\mathrm{a}}$ & $72,89^{\mathrm{a}}$ & $16,54^{\mathrm{a}}$ & $89,44^{\mathrm{a}}$ \\
Dorper & & & & & & \\
Morada Nova & & $63,96^{\mathrm{d}}$ & $64,33^{\mathrm{e}}$ & $74,64^{\mathrm{a}}$ & $11,95^{\mathrm{e}}$ & $90,71^{\mathrm{a}}$ \\
\hline
\end{tabular}

$\mathrm{AG}=$ altura de garupa; $\mathrm{AC}=$ altura de cernelha; $\mathrm{CC}=$ comprimento corporal; $\mathrm{CO}=$ comprimento de orelha; $\mathrm{CIRC=}$ circunferência torácica; $\mathrm{LIT}=$ Litoral Piauiense; VAL= Valença do Piauí; $A M G=$ Alto Medio Gurguéia; SRN= São Raimundo Nonato; CAM= Campo Maior; FLO= Floriano; MPP= Médio Parnaíba Piauiense; THE= Teresina.

a,b,c,d,fMédias seguidas de mesma letra na coluna não diferem ( $p>0,05)$ pelo teste Student-Newman-Keuls.

grupos, foi formada pelo cálculo da menor diferença entre a soma de quadrado ponderada do novo grupo e a soma ponderada da soma de quadrado dos grupos aglutinados para formar o novo grupo.

Foram calculadas as médias das medidas corporais dos grupos de animais formados pela análise de agrupamento pelo método Ward e comparados com os animais dos genótipos de ovinos Dorper e Morada Nova (tabela V), a partir do que se percebe que os animais do grupo 4, formado pelas microrregiões de Campo Maior, Floriano, Médio Parnaíba Piauiense e Teresina, possuem maiores medidas, seguido do grupo 2, 3 e 1, respectivamente.

Pode-se classificar os animais pertencentes ao grupo 4 como animais maiores, mais compridos, de grande circunferência torácica e de maior comprimento de orelha, animais parecidos com a descrição de Paiva et al. (2005) para o Novo Santa Inês, que pode estar associado à ideia dos animais serem mais compridos e provavelmente mais robustos, não se diferenciando estatisticamente da raça Dorper em relação às medidas de comprimento corporal e circunferência torácica. Os animais do grupo 2, composto por exemplares pertencentes à microrregião do Alto Médio Gurguéia, são de porte intermediário, já os animais de menor porte estão agrupados no primeiro grupo, sendo que esses animais possuem a particularidade de apresentarem o comprimento de orelha intermediário, diferentemente dos animais do terceiro grupo que possuem porte intermediário com alto valor de circunferência torácica e pequeno comprimento de orelha (tabela $\mathrm{V}$ ).

Ainda com relação às características morfológicas, também se pode utilizar uma ferramenta da análise multivariada que é a análise de correspondência, a qual pode mostrar qual característica possui maior correspondência com qual grupo de animais ou raça. Para essa análise, estudou-se a correspondência (figura 5) da característica tipo de pelo e tipo de perfil de chanfro com as raças de ovinos Dorper e Morada Nova, juntamente com os grupos de animais da raça Santa Inês formados de acordo com a microrregião, pela análise de agrupamento pelo método Ward, discutido anteriormente.
Através da análise por correspondência percebe-se que os animais da raça Dorper possuem alta correspondência com a característica lanado, mais que qualquer outro grupo; animais da raça Morada Nova possuem alta correspondência com a característica deslanados; enquanto que animais do grupo 1 , formado pela microrregião do Litoral Piauiense e Valença, e grupo 4, pelas microrregiões de Campo Maior, Floriano, Médio Parnaíba Piauiense e Teresina, possuem alta correspondência com a característica de chanfro semi-convexo. Já os animais do grupo 2 possuem alta correspondência com a característica lanugem e o tipo de chanfro retilíneo, enquanto os animais do grupo 3 composto por animais da microrregião de São Raimundo Nonato estão mais correlacionados à característica de chanfro convexo. A análise de correspondência revela que alguns grupos possuem características indicadoras de cruzamento com raças lanadas, como, por exemplo, a característica de presença de lanugem.

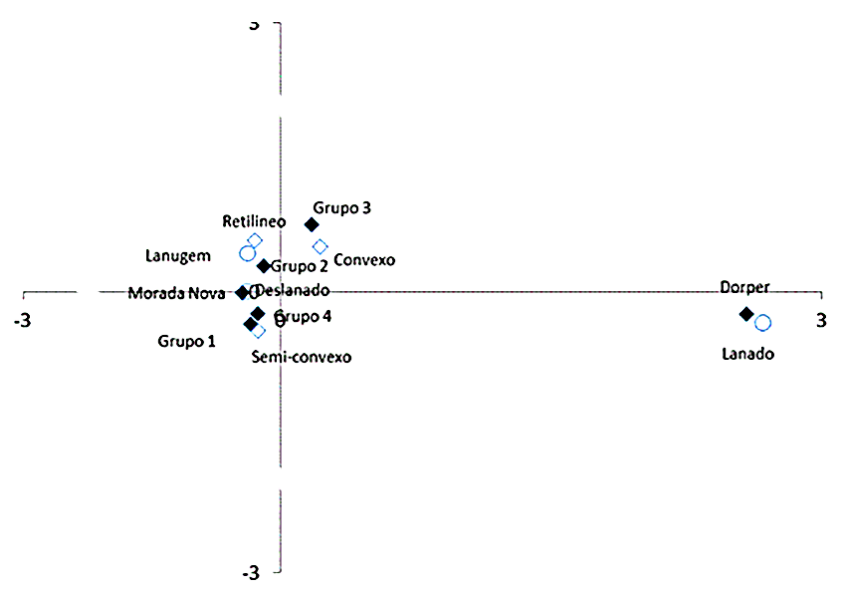

Figura 5. Dispersão referente à análise de correspondência entre as características morfológicas do tipo de pelo $(\circ)$ e perfil do chanfro $(\diamond)$ em relação aos grupos formados pela análise de agrupamento pelo método Ward ( $\$$ (Dispersion on the correspondence analysis between the morphological characteristics of the type of hair $(0)$ and chamfer profile $(\bullet)$ for the groups formed by the cluster analysis by Ward $\operatorname{method}(\bullet))$. 


\section{CONCLUSÃO}

As características métricas avaliadas por meio de análise multivariada indicam que entre a raça Santa Inês e Dorper existe maior semelhança morfométrica do que em relação à raça Morada Nova.

As características morfológicas avaliadas, o tipo de pêlo e perfil do chanfro são indícios que pode estar ocorrendo cruzamentos de animais da raça Santa Inês com animais da raça Dorper.

As características biométricas que mais contribuíram para a identificação dos grupos semelhantes de animais foram à altura de cernelha, a altura de garupa e o comprimento de orelha.

Animais da raça Santa Inês no Estado do Piauí criados na microrregião do Alto Médio Gurguéia, Litoral Piauiense e Valença parecem estar morfometricamente pouco associado à raça Dorper.

\section{BIBLIOGRAFIA}

Bueno, M.S.; Cunha, E.A. e Santos, L.E. 2001 . Características de carcaça de ovinos Santa Inês abatidos com diferentes idades. Arch Zootec, 50: 33-38.

Carneiro, H.; Louvandini, H.; Paiva, S.R.; Macedo, F.; Mernies, B. and McManus, C. 2010. Morphological characterization of sheep breeds in Brazil, Uruguay and Colombia. Small Ruminant Res, 94: 58-65.

Cartaxo, F.Q.; Sousa, W.H.; Cezar, M.F.; Gonzaga Neto, S. e Cunha, M.G.G. 2008. Efeitos do genótipo e da condição corporal sobre o desempenho de cordeiros terminados em confinamento. Rev Bras Zootecn, 37: 1483-1489.

Cruz, C.D. e Carneiro, P.C.S. 2006. Modelos biométricos aplicados ao melhoramento genético, $2^{a}$ ed. Ed. da UFV. Viçosa. 585 pp.

Cruz, C.D. 2008. Programa Genes: aplicativo computacional em genética. Versão 6.0. UFV. Viçosa.
Dias, C.T.S. 2009. Análise multivariada. (Notas de aula-Apost1 4) Escola Superior Luis de Queiroz-ESALQ. Piracicaba-SP.

Dossa, L.H.; Wollny, C. and Gauly, M. 2007. Spatial variation in goat population from Benin as reveled by multivariate analysis of morphological traits. Small Ruminant Res, 73: 150-159.

Greenacre, M.J. 2007. Correspondence analysis in practice. $2^{\text {nd }}$ ed. Chapman \& Hall/CRC. United Kingdom.

IBGE. 2010. Pesquisa pecuária municipal (PPM). http://seriesestatisticas.

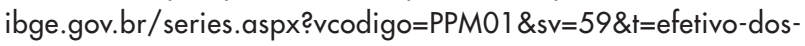
rebanhos-por-tipo-de-rebanho (17/04/2013).

Neto, A.C; Lui, J.F.; Ribeiro, M.N.; Malavolta, F.C. e Coelho, J.G. 2006. Estudo de características de tipo em coelhos da raça Nova Zelândia Branca no Estado de São Paulo. Rev Caatinga, Mossoró, 19: 76-81.

Oliveira, J.C.V.; Rocha, L.L.; Ribeiro, M.N. e Gomes Filho, M.A. 2006. Caracterização e perfil genético visível de caprinos nativos no Estado de Pernambuco. Arch Zootec, 55: 63-73.

Paiva, S.R.; Silvério, V.C.; Egito, A.A.; McManus, C.; Faria, D.A.; Mariante, A.S.; Castro, S.R.; Albuquerque, M.S.M. and Dergam, J.A. 2005. Genetic variability of the Brazilian hair sheep breeds. Rev Agropecu Bras, 40: 887-893.

Rencher, A.C. 2002. Methods of multivariate analysis. $2^{\text {nd }}$ ed. Wileyinterscience. New York. 708 pp.

Rohlf, F.J. 1970. Adaptative hierarquical clustering schemes. Syst Zool, 19: 58-82.

Selaive-Villarroel, A.B. e Souza Júnior, F.A. 2005. Crescimento e características de carcaça de cordeiros mestiços Santa Inês e Somalis x SRD em regime semi-intensivo de criação. Ciênc Agrotec, 29: 948-952.

Sokal, R.A. and Rohlf, F.J. 1962. The comparison of dendograms by objective methods. Taxonomy, 11: 33-40.

Traoré, A.; Tamboura, H.H.; Kabore, A.; Royo, L.J.; Fernández, I.; Álvarez, I.; Sangare, M.; Bouchel, D.; Poivey, J.P.; Francois, D.; Toguyeni, A.; Sawadogo, L. and Goyache, F. 2008. Multivariate characterization of morphological traits in Burkina Faso sheep. Small Ruminant Res, 80: 62-67. 